\title{
Suppression and recovery of mouse killing in rats following immediate lithium-chloride injections*
}

\author{
MICHAEL O'BOYLE, THOMAS A. LOONEY \\ and \\ PERRIN S. COHEN \\ Florida State University, Tallahassee, Fla. 32306
}

Immediate $\mathrm{LiCl}$ injections temporarily suppressed rats' mouse killing. The $\mathrm{LiCl}$ dosage used to suppress killing was the same as that previously used to produce taste aversion learning in rats. The suppression of mouse killing was not due to the injection procedure alone or to the residual physiological effects of $\mathrm{LiCl}$. These results indicate that toxic drugs can be used to suppress behaviors other than eating and drinking.

Conditioning studies (Rozin \& Kalat, 1971) have demonstrated that toxic drugs can be used to suppress a highly probable behavior. In a typical experiment, Ss that are exposed to a highly palatable food (or fluid) and then injected with a toxic drug subsequently avoid ingesting the palatable substance. For example, Nachman (1970) has demonstrated that, if thirsty rats are given $10 \mathrm{~min}$ access to a highly palatable saccharin solution and then injected with a toxic dosage of a lithium chloride ( $\mathrm{LiCl}$ ) solution, those rats will avoid drinking saccharin solution in a subsequent test session. Since these conditioning studies using toxic drugs have been primarily concerned with the modification of eating and drinking, the question occurs as to whether this is a highly specialized type of conditioning (Rozin \& Kalat, 1971) unique to ingestive responses or a more general type applicable to other types of behaviors. As a first step in answering this question, the present study examined the effect of injecting a rat with a toxic dosage of a lithium chloride solution immediately after it killed a mouse. Control procedures were used to demonstrate that suppression of mouse killing was due to the pairing of the mouse and/or killing behavior with a lithium chloride injection rather than to either the long-term residual effects of the drug or the injection procedure alone.

Although there is evidence that stereotyped mouse killing (approach and repeated biting of the back of the neck) observed in some rats can be initiated by food deprivation (Paul, Miley, \& Baenninger, 1971), it is, on the other hand, functionally distinct from eating in that the rat does not necessarily eat the mouse (Paul, 1972;

*Sponsored by Michael E. Rashotte, who takes full editorial responsibility for the paper. Supported in part by Psychobiology Research Center (U.S. Public Health Service Grants NB-7468 and MH 11218 and National Science Foundation Grant GU 2612). We Michael S. Loop, Lewis M. Barker, and Robert W. Griffin.
Van Hemel, 1972). Furthermore, there is additional evidence that mouse killing and eating in rats are controlled, to some extent, by different physiological mechanisms (Karli, Vergnes, \& Didiergeorges, 1969).

\section{METHOD \\ Subjects}

Thirteen adult male albino Holtzman rats (160-190 days old) that had previously been maintained at $80 \%$ of their free-feeding weights in an operant conditioning experiment and that had had no prior exposure to mice or drugs were used as Ss. They were individually housed in a room having a 12-h light-dark cycle (light from 7:00 a.m. to 7:00 p.m.). Food and water were available throughout the study.

\section{Apparatus}

All rats were tested in their home cages (Hoeltge Model LC-75/A), which had stainless steel sides and back, and a grid front and floor ( $25 \times 18 \times 18 \mathrm{~cm}$ high).

\section{Procedure}

After a 10-day adaptation period, during which the rats returned to their free-feeding weights, each rat was tested for mouse killing over three consecutive daily sessions. During each test session, one adult mouse was placed in the rat's cage. Heterogeneous laboratory mice weighing from 20 to $30 \mathrm{~g}$ were used as prey. The bodies of mice that were killed were removed within $50 \mathrm{sec}$ after a kill to assure that the rat did not eat the mouse. If the rat did not kill the mouse, the live mouse was removed after $30 \mathrm{~min}$. During this screening procedure, 6 of the 13 rats killed every mouse presented within $3 \mathrm{~min}$ and served as Ss for the remainder of the study. These six rats were randomly divided into three pairs. The experimental and control procedures, as well as the results, are summarized in Table 1. One pair (Rats 1 and 2) received lithium chloride injections (2\% body weight of $.15 \mathrm{~m} \mathrm{LiCl}$, ip) immediately $(<1 \mathrm{~min})$ after killing a mouse. As previously mentioned, this dosage of lithium chloride solution has been found to reliably produce conditioned taste aversions in the rat (Nachman, 1970). The second pair (Rats 3 and 4 ) received saline injections ( $2 \%$ body weight of $.15 \mathrm{~m} \mathrm{NaCl}$, ip) immediately $(<1 \mathrm{~min})$ after each kill. The third pair (Rats 5 and 6) was untreated. Injections were continued for 3 days (Days 4-6) or until a rat failed to kill a mouse in a 30-min trial (a no-kill trial). The first pair (Rats 1 and 2, immediate lithium chloride) received no further injections in the experiment but continued to receive daily mouse presentations until they had killed within a 30 -min trial over 3 consecutive days. On Days 7 and 8, no rats were injected. On Days 9-11 one rat from the saline pair (Rat 3) and one rat from the no-treatment pair (Rat 5) received lithium chloride injections immediately after killing. The remaining two rats (Rats 4 and 6) were injected with lithium chloride $3 \mathrm{~h}$ after they killed. Again, if no kill occurred within a 30 -min trial, the mouse was removed and no injection was given. No injections were given on Days 12 and 13. On Days 14-16, Rats 4 and 6, which previously received delayed lithium chloride injections, were injected with lithium chloride immediately after killing. Again, if no kill occurred within a 30-min trial, no injection was given. No further injections were given after Day 16 , but each rat continued to receive daily mouse presentations until it met the recovery criterion of a kill within a 30 -min trial for 3 consecutive days. 


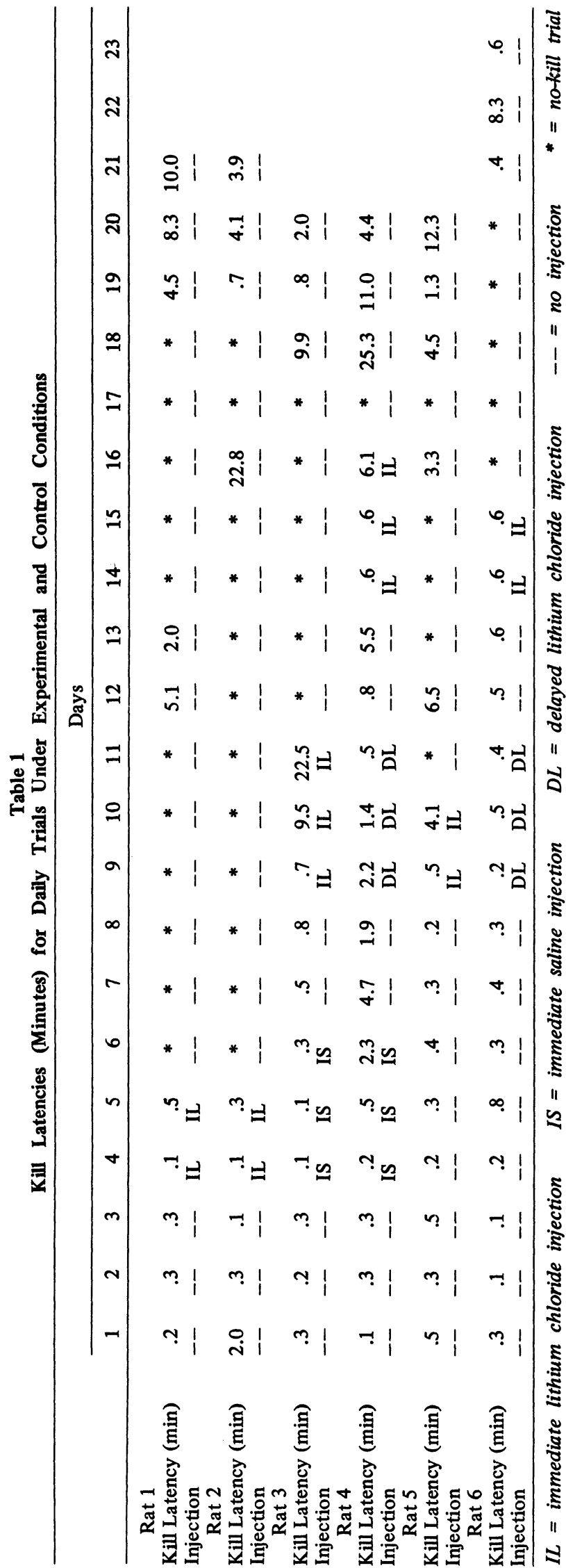

Kill times were recorded by one observer. Reliability was checked on 24 of the 125 trials by having a second observer independently record kill latencies. Agreement on latencies was high, with differences in recorded latencies never exceeding $10 \mathrm{sec}$.

\section{RESULTS AND DISCUSSION}

The results (Table 1 ) clearly show that immediate lithium chloride injections in the same dosage used to produce learned taste aversions suppressed mouse killing in rats. All rats showed at least a $300 \%$ increase in kill latency, with at least one failure to kill following immediate lithium chloride injections; whereas, no rat failed to kill a mouse prior to receiving immediate lithium chloride injections. This effect was not due to the injection procedure alone or to the residual physiological effects of the lithium chloride injections, since rats receiving either immediate saline or delayed lithium chloride injections were relatively unaffected (Rat 4 showed a small increase in kill time on Days 5-7 after the saline injections).

Observations of the rat-mouse interaction on trials in which mouse killing was suppressed indicated that the rat would often approach the mouse and then withdraw in a way similar to that previously reported in other studies involving the punishment of mouse killing with electric shock (Myer \& Baenninger, 1966). In many instances, the rats in the present study would approach the mouse to the point where it would pick the mouse up in its mouth, carry it about, and then drop it. On other occasions, the rat would approach, chew on the mouse's tail or foot, and then withdraw.

The fact that lithium chloride injections can be used to suppress mouse killing raises the question of how this result is related to the previous experiments on taste aversion learning that have also used lithium chloride injections. The number of sessions required to reach the recovery criterion of three consecutive kill trials was inversely related to the number of mouse presentations prior to the immediate lithium chloride injections. This may be related to taste aversion studies (Revusky \& Bedarf, 1967; Wittlin \& Brookshire, 1968) which found less learned aversion to familiar, as opposed to novel, tastes. It is not clear from the results what cue(s) controlled the rat's avoidance behavior on trials following an immediate lithium chloride injection. While gustatory stimulation might have controlled the rat's behavior, as in taste aversion learning, it is possible that the behavior was under the control of proprioceptive feedback from biting, olfactory cues, or visual stimulation. Regardless of what cue controlled the avoidance behavior, it would be of interest to determine if taste aversion learning reported in other studies and the suppression of mouse killing observed in this one are influenced in the same way by comparable variations of the conditioning procedure. For example, it might be the case that different punishers (e.g., X-radiation) and different response-punisher intervals that have been effective in producing a conditioned taste aversion 
(Smith \& Roll, 1967; Nachman, 1970) would also be effective in suppressing mouse killing.

\section{REFERENCES}

Karli, P., Vergnes, M., \& Didiergeorges, F. Rat-mouse interspecific aggressive behavior and its manipulation by brain ablation and by brain stimulation. In S. Garattini and E. B. Siggs (Eds.), Aggressive behavior. Amsterdam: Excerpta Medica Foundation, 1969.

Myer, J. S., \& Baenninger, R. Some effects of punishment and stress on mouse killing by rats. Journal of Comparative \& Physiological Psychology, 1966, 62, 292-297.

Nachman, M. Learned taste and temperature aversion due to lithium chloride sickness after temporal delays. Journal of Comparative \& Physiological Psychology, 1970, 73, 22-30.

Paul, L. Predatory attack by rats, its relationship to feeding and type of prey. Journal of Comparative \& Physiological Psychology, 1972, 78, 69-76.

Paul, L., Miley, W. M., \& Baenninger, R. Mouse killing by rats:
Roles of hunger and thirst in its initiation and maintenance. Journal of Comparative \& Physiological Psychology, 1971, 76 , 242-249.

Revusky, S. H., \& Bedarf, E. W. Association of illness with prior ingestion of novel foods. Science, 1967, 155, 219-220.

Rozin, P., \& Kalat, J. Specific hungers and poison avoidance as adaptive specializations of learning. Psychological Review, $1971,78,459-486$.

Smith, J. C., \& Roll, D. L. Trace conditioning with $\mathrm{X}$-rays as an aversive stimulus. Psychonomic Science, 1967, 9, 11-12.

Van Hemel, P E. Aggression as a reinforcer: Operant behavior in the mouse-killing rat. Journal of the Experimental Analysis of Behavior, 1972, 17, 237-245.

Wittlin, W. A., \& Brookshire, K. H. A pomorphine-induced conditioned aversion to a novel food. Psychonomic Science, 1968, 12, 217-218.

(Received for publication January 15, 1973.) 